\title{
Reimagining the Ruins of Scenography
}

Tanja Beer

Opening night at the theater and the stage is awash with color and spectacle, an aweinspiring display of set and costume extravagance. Fast-forward eighteen months: this wondrous design has transformed itself into a mountainous ruin, oozing from a gluttonous skip deep in the bowels of the building. These contemporary "theater ruins" begin relatively harmlessly, hidden behind dusty staircases and at the back of storage units, crowding corridors and littering dressing rooms. But sooner or later, what doesn't make it into the recycle bin is cast off to the land of "away," where skips overflow into leaching landfills, and, inextricably, into our fragile ecosystems. It is here that we encounter the unsettling reality that our arts practices have consequences.

The ephemeral and highly specific nature of theatrical work means that most set and costume designs are only valued for the duration of the performance season (often a matter of days or weeks) before they are discarded. ${ }^{1}$ Designers are rarely contracted to consider the impact of their designs after opening night, or to build post-production possibilities into their creative processes. But does it need to be this way? Can the image of the skip as the final resting place of most theatrical designs instead be revised to find another endpoint where creativity and innovation can once again flourish? How might scenographers embrace cyclic rather than linear production processes to rethink the potential of art's refuse?

This essay explores the role of the scenographer in seeking out the artistic potential of unconventional materials and discarded objects in and beyond the theater. Here, extending the use of materials is not approached out of austerity but fueled by a desire for invention and ingenuity - a way of rethinking design in response to ecological values. Moving beyond the transient nature of performance design, I ask whether post-production considerations can 
become an integral component of the design concept and thereby extend the legacy of the project. I consider how the temporality of scenic design can be reexamined so that the "endpoint" of production is no longer seen as waste, but becomes an opportunity (intellectual as well as material) for continuing the creative process itself.

Central to this investigation is a reconsideration of notions of value in and beyond the theater. Instead of concentrating on waste reduction through the reuse of objects, the focus of this research is to examine how recycled materials and found objects can generate value and make a contribution beyond the restricted theatrical economy of production. For example, a set designer might seek out the untapped creative possibilities of readily available resources (such as stock items, found objects, and discarded materials), or materials that might ordinarily be rubbished or otherwise devalued, as a means of creating something of beauty and resonance that might also extend beyond the performance event.

This essay begins by introducing the concept of ecoscenography, a practice I define as the integration of ecological thinking into all stages of scenographic production and aesthetics. ${ }^{2}$ Rethinking conventional production processes, I examine contemporary thinking about material culture and agency through the scenographer's practice of "making." Using a practice-based research project—This Is Not Rubbish, which began in December 2012 and unfolded in four phases over a span of two years-I explore the journey of material rescued from the landfill and its capacity to create immersive performance spaces and wearable artifacts.

This Is Not Rubbish considers how post-production procedures may be considered an integral part of the scenographic event and its broader artistic project. ${ }^{3}$ The project situates itself in the field of expanded scenography, ${ }^{4}$ where scenographic practices are considered outside of "conventional roles and sites of theater" 5 to engage with broader issues of social and environmental advocacy. While This Is Not Rubbish was conducted primarily outside of 
traditional contexts of theater making (to enable greater flexibility to explore novel ideas and approaches), this essay also considers potential applications of the project to conventional theater design practices as well.

\section{An Introduction to Ecoscenography}

"Ecoscenography" is a neologism I use to bring scenography into an increased awareness of broader ecologies and global issues: to conceptualize ways in which an ecological ethic can be incorporated into scenographic practices. ${ }^{6}$ The concept differs from more conventional approaches to sustainability in stage design (such as eco[efficiency) that strive primarily to minimize ecological impacts rather than to activate new social, cultural, and environmental potentialities. Instead of limiting resources in response to concerns about sustainability, ecoscenography considers how ecological and artistic integrity can be a fundamental part of the scenographer's very ideas, processes, and aesthetics.

A central component of ecoscenography is the notion that the scenographer makes an environmental and social contribution beyond the theatrical work itself. Here the quality and success of a design is measured not only by the phenomenological or aesthetic experiences it yields, ${ }^{7}$ but also by the environmental and social systems to which it relates and contributes. This entails a more comprehensive understanding of ecological aesthetics that relates to the "intellectual and affective capacities [that] engage an individual to understand, appreciate and ultimately act upon the environment in a [positive and] purposeful way." ${ }^{8}$ Simply put, ecological aesthetics asks us to consider how something can possibly be considered to be "beautiful" if it taxes and degrades living ecosystems. It asks us to reorient our aesthetic judgement to focus on the ecological integrity of a material, object, or experience- to reconsider our appreciation for things based on a greater understanding and concern for social-ecological systems. 
Ecoscenography hinges on the awareness that no decision stands on its own: every material choice is intertwined with social, environmental, economic, and political consequences that are far-reaching and capable of having long-term effects. ${ }^{9}$

\section{Value and Upcycling}

Reconceiving notions of value in material culture leads to a unique perspective on the cyclic and continuous potentiality of material things in ecoscenographic practice.

Anthropologist Igor Kopytoff uses the term "cultural biography" to refer to the way in which an object or material can acquire and shed value under different circumstances throughout time. ${ }^{10}$ Similarly, for sociologist Tim Dant, the value of a thing comprises the accumulated investitures of its origin, the history of those who have acquired it, and their practices of exchange. ${ }^{11}$ For consumer theorist Liz Parsons, however, value also emerges through our ways of perceiving such things. ${ }^{12}$ Transforming something of little economic value into an upcycled object of augmented value results from a relatively minor shift in the contexts and configurations in which we see it. ${ }^{13}$ Here, value is not fixed but negotiable according to our perception and our practices of endowing something with meaning and opening up creative possibilities for transformation. From an ecoscenographic perspective, the task of generating value becomes one of "respecting" an object's potential through the creative process.

Cultural theorist Michael Thompson stresses the creativity necessary for looking beyond an object's intended function and for seeking out the beauty in unconventional materials. ${ }^{14}$ Yet it is often the idea of reconstituting or reappropriating discarded materials that activates the creative process. For many scenographers, inspiration comes from a serendipitous relationship with found objects and an unconventional reuse of materials. Whereas working with discarded materials and found objects in scenographic practice is a common occurrence, ${ }^{15} \mathrm{I}$ am interested in how designers might work beyond conventional 
processes and aesthetics to reimagine the performance season (or ultimately, closing night) as an activation point instead of an endpoint, a stimulus for further making, recirculation, and reappreciation.

The idea that "rubbish" objects and materials might be revalued and repurposed has been most recently propagated by the "upcycling" movement. A term first coined by Reiner Pilz in 1994, upcycling defines the process of transforming a material into something of similar or greater value. ${ }^{16}$ The concept was made popular by William McDonough and Michael Braungart in their book The Upcycle (2013) and stands in contrast to recycling. ${ }^{17}$ Upcycling is about "not merely conserving the resources that went into the production of particular materials, but adding to the value embodied in them by the application of knowledge in the course of their recirculation." 18 It involves upvaluing rather than just reusing things. Textile designer Rebecca Earley provides a practical definition: "if one can add value - economic, intellectual, emotional, material — to a product through the process of reuse," she writes, "it can be called 'upcycled.",19

Parsons explains how the impetus to upcycle emerges through the acts of finding, displaying, transforming, and reusing objects. ${ }^{20}$ Each of these sets of practices changes the way we view an object, transforming its value from an exhausted capacity of usefulness or significance to an index of new sets of opportunities. For example: the act of "finding" entails discovering or rediscovering something that might previously have been overlooked, ignored, or hidden away; the operation of "displaying" reveals how the presentation of an object affects its reverence or distinction in worth; and the processes of "transforming and reusing" highlights the opportunistic and creative nature of alteration through reconstruction or repurposing. Parson's categories demonstrate the various ways in which a scenographer might engage with phenomenological and ecological aesthetics through the act of continuous repurposing. 


\section{The Ontogenesis of Making}

The act of upcycling requires a haptic engagement with materials and hands-on participation in constructive labor. For example, Broadway set designer and sustainability advocate Donyale Werle describes her process of working with salvaged materials as one of literally rummaging through garbage to find treasures and ideas that fuel her creative process. Werle's willingness to seek out the potential of devalued, discarded, or discredited materials is facilitated through her hands-on connection and direct engagement with things. As she explains in an interview in American Theatre, "Any kind of trash can be material. . . You get this stuff and you wrestle with it. ... All the time, I'm like, 'Okay, this is what we've got. This is what's in front of us. How do we use it?"'21

Werle's work demonstrates how the process of repurposing arises out of the serendipitous qualities of, and multisensory interaction with, available materials. The broader task of transforming or remaking opens up to at once to sensory and perceptual experience (e.g., visual, audible, kinaesthetic, tactile, olfactory, somatic, gustatory, spatial, and durational) and accumulates experientially through the reciprocal connections of perceiver and object. ${ }^{22}$ According to anthropologist Tim Ingold, such an engagement breaks with the hylomorphic model of creation that assumes the artist to be an agent imposing form on an inert substance incapable of exerting its own agency. ${ }^{23}$ Instead the act of making inaugurates a process of development or ontogenesis, which means that forms and structures arise out of emergent and improvised processes rather than playing out according to a predetermined plan or image. Such practices recall Gilles Deleuze's and Félix Guattari’s idea of “matter-flow," which implies "surrendering" to the material, and "following where it leads." 24

Integrating aspects of flow, embodiment, and material agency, Ingold explains how an ontogenesis approach requires a change of focus from the "objectness of things" to an engagement with the qualities and possibilities of material. ${ }^{25}$ To view an object as material is 
to see beyond the contexts and semiotics that humans have imposed upon them-to recognise its potential for further value through processes of making and transformation. ${ }^{26}$ As highlighted above, this distinction opens up ecological possibilities for scenographers to rethink the potential and value of discarded objects, not as "finished" or exhausted but instead as continuous "avenues for becoming."

Considered broadly, the practice of making can be seen as a negotiation between material and human action and resonates with quantum theorist Karen Barad's notion of "intra-action." Extending beyond "interaction" (that which occurs between distinct entities), intra-action refers to a fundamental and co-creative entanglement between individual entities in the flow of making. ${ }^{27}$ Intra-action involves moving away from binaries that separate matter from agency, and human from nonhuman, and instead embracing the complex intrarelationships between all things. For Barad, nothing exists as a thing-in-itself but is "worlding in its materiality ... [of] ongoing historicity." 28 In other words, matter as "intraactive becoming" 29 synthesizes the connections between the fluidity of interfaces, interchanges, and transformations that extend between and among the circulation of objects and the processes of creation and perception. As Barad contends, to deny matter "as an active participant in the world's becoming" is to disengage with the flow of making. ${ }^{30}$

Ingold's and Barad's emphasis on the active potential of matter is an opportunity for scenographers to change the ways in which they approach their own creative processes. This involves a transition of the scenographer from a mere manipulator of forms to a mediator, facilitator, and co-creator who participates in a flow of imaginative exchanges. My own process in making This Is Not Rubbish explored the possibilities of such a transformation; the changing role of the scenographer become the very focus of the performances themselves, which extended the integrative creative process into the very structure of the spectacle. 


\section{This Is Not Rubbish}

In December 2012, I initiated an investigation under the title This Is Not Rubbish, a project that examined the journey of a material rescued from landfill and its capacity to create immersive performance spaces and wearable artifacts. Transported in a small suitcase or backpack, the work sought to challenge preconceptions about what is considered rubbish, as well as the need for scenographers and performance makers to continuously begin anew in a world of increasing environmental concerns. This Is Not Rubbish explores ways in which ideas of reuse, circularity, and value might be incorporated into scenographic thinking and post-production.

The project incorporated four cycles of action research ${ }^{31}$ allowing the work to evolve through three performance iterations, entitled Strung, and one crafting project, This Is Not Rubbish Craft Circle, which took place in a variety of international contexts (see fig. 1). The central phase of This Is Not Rubbish was Strung, an ecoscenographic demonstration performed with one bag of salami netting off-cuts, one performer, one musician, and three active scenographers who worked together to build an installation directly in front of the audience. After the final showing of Strung, I set up a craft circle as part of my residency at the Royal Central School of Speech and Drama in London (Central) to knit the material into wearable art and auction off the items for charity. ${ }^{32}$

The aims of This Is Not Rubbish were, first of all, to challenge the ephemeral and highly specific nature of scenographic work by eliminating landfill waste in the production of sets and costumes; and second, to examine nonlinear approaches to scenography through which post-production processes and distribution become a crucial part of the design aesthetic and outcome. The objective was not to create a finished artwork, but to use the performance as a testing ground for exploring materiality and repurposing in the public 
realm. This Is Not Rubbish also advocated for a cognitive and sensory approach to aesthetics that engaged embodied perception ${ }^{33}$

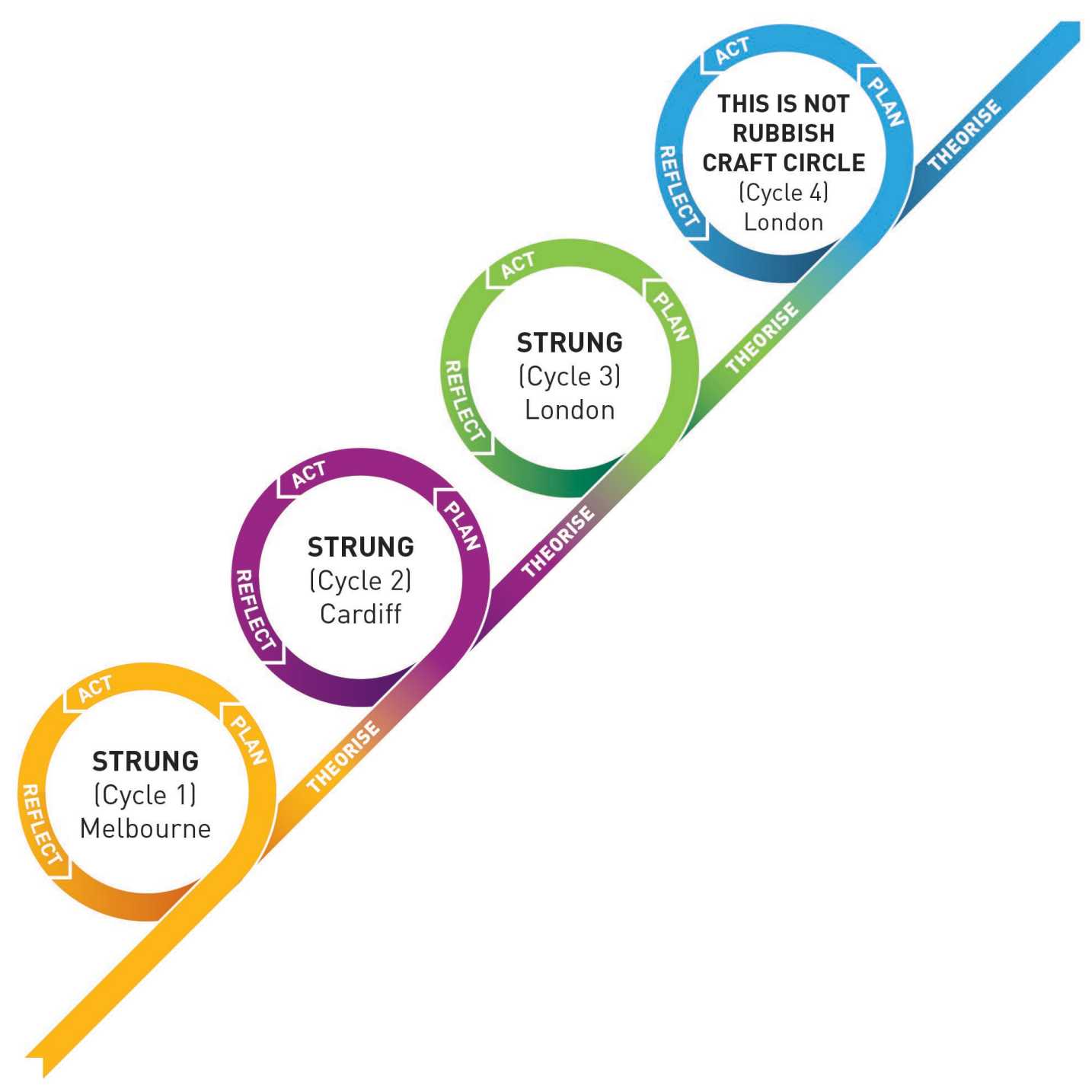

Fig. 1 Iterations of This Is Not Rubbish. (Image courtesy of the author.)

I explored notions of material value and agency throughout the project's development, from my first discovery of the salami netting through the various performative iterations of This Is Not Rubbish and, ultimately, to the production and auction of wearable items from the 
set. Throughout its various stages, Parsons' categories of "value creation" - the finding, transformation, display, and reuse of materials — offered a guiding structure and iterative process for understanding the development of the project. ${ }^{34}$

\section{Strung (Cycle 1): Finding and Seeking}

In December 2012, I received a commission from the Victorian Arts Centre (Melbourne, Australia). The brief was relatively open: to create a small ecoscenographic performance installation to accentuate and incorporate the architectural elements of the foyer of the Centre's main performance space, Hamer Hall. I chose string as a possible material for the design because of its potential literally to connect architectural elements in the Centre and for its flexibility as a material that could be reused after the performance. I made a trip by train to Melbourne to a recycled art supply business, Reverse Art Truck, to buy a backpack full of reclaimed string or fabric that would inspire the design.

As Parsons suggests, our serendipitous relationship with found objects opens up opportunities to activate imagination. ${ }^{35}$ Walking through Reverse Art Truck in pursuit of a material, ${ }^{36}$ I recall the rush of excitement and feelings of creative possibility I experienced as I sought out such serendipitous discoveries. The act of finding required my ability to seek out the potentiality of things as both "objects" and "materials." In other words, when I viewed something as an object, I saw it in terms of its prior use, functionality, identity, and status. Viewing the same thing as material meant seeing it instead as an actant for further making and transformation. ${ }^{37}$ These two distinct ways of seeing challenged my own initial ambivalence toward the materials I selected. When I first saw the salami netting off-cuts I ultimately chose for the performance, they seemed far from ideal, almost ugly and useless in their shape and form. It was only when I chose to examine the material more closely, literally taking it up and holding it in my own hands, that I recognized its potential in closer 
proximity. Exploring the variability of the netting, "its tensions and elasticities, lines of flow and resistances, ${ }^{38}$ revealed a flexibility and strength that opened up ideas for creative spatial investigation, in tandem with the conceptual associations it evinced (fig. 2). Scenographer Pamela Howard suggests that objects and materials have their own innate beauty and theatrical power and it is up to the designer to seek out their potentiality. ${ }^{39}$ However, perhaps our ability to identify desirable things is not always instantaneous; as I discovered, things that appear resistant and hostile at first can also become exciting materials for engagement. ${ }^{40}$

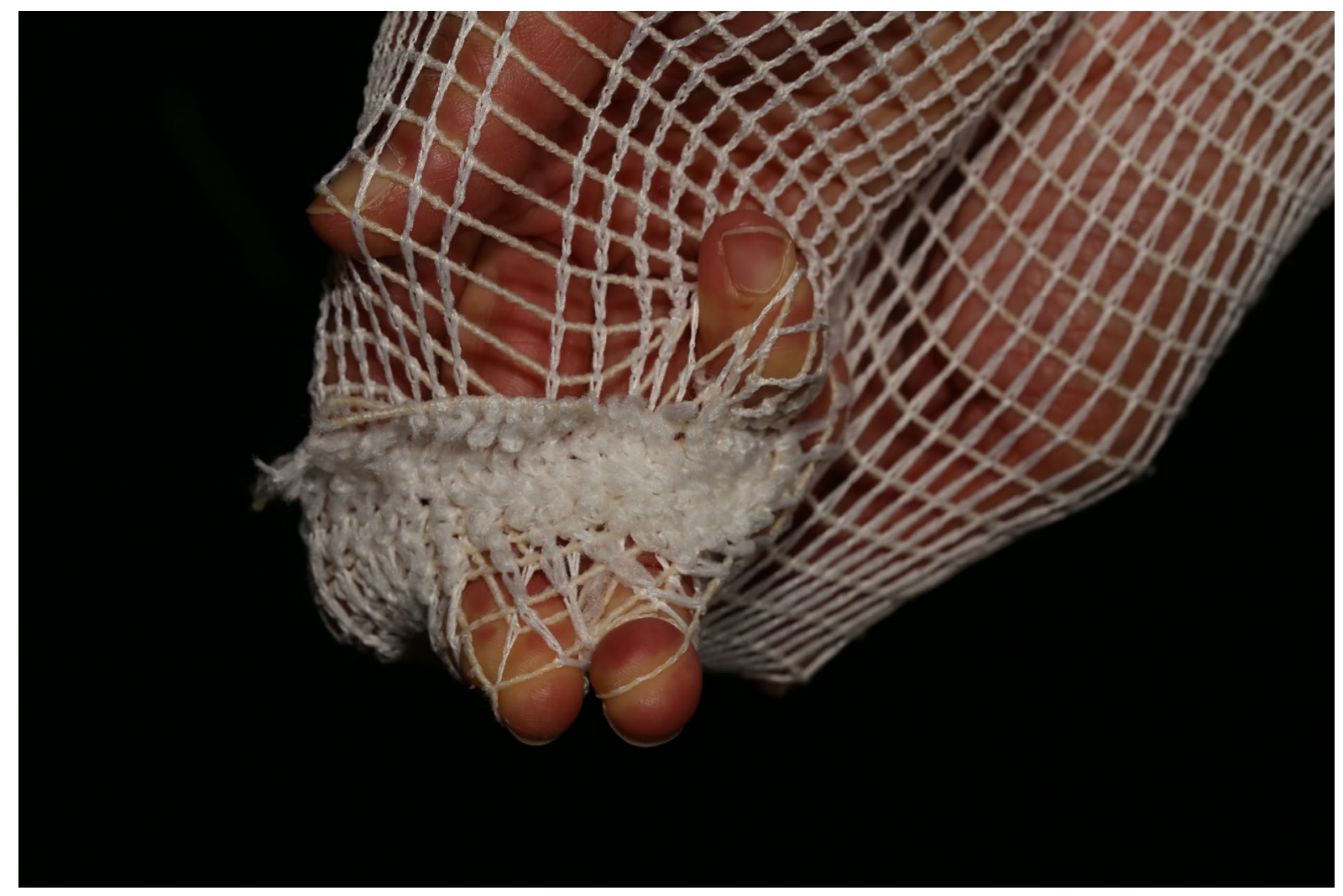

Fig. 2. Salami netting material. (Photo: T .Beer. Image courtesy of the author.)

There is a particular excitement that comes with reappraising things we do not immediately recognize as valuable. "These are things that we cannot name and make sense of ... but we can get excited about discovering it and exploring the possibilities it incorporates," as Dant puts it. ${ }^{41}$ The original intention of the material (salami netting) was unknown to me at the time of purchase, and I discovered its prior employment only shortly before the first 
performance. For me, not knowing the object's original purpose was advantageous insofar it meant that its theatrical potential derived from thinking "from the materials, not about them." 42 In this case, I approached the material not according to my knowledge of what it was or what it should do, but according to my ability to engage with what it could do. It required an open-mindedness and willingness to interact more responsively with the relational potentiality and integrity of the material.

Nevertheless, the choice of salami netting also had something to do with the lack of availability of the string-like material I had originally been seeking. This (supposed) limitation was nonetheless salutary in itself, insofar as it prompted me to reconsider the qualities of things I might otherwise have overlooked, ignored, or hidden away. Scarcity often directs us to other potentialities, objects, or materials that we may have already looked at, but rediscover on a second or third viewing, finding them only at that point "to be useful, likeable or beautiful," as Parsons puts it. ${ }^{43}$ When I realized that my preconceived idea of the perfect material was not available, my objectives necessarily became more flexible, my thinking more lateral. I had to allow myself to seek out the potentiality of unlikely objects.

\section{Strung (Cycle 1): Transforming and Correspondence}

There is a link between the scenographer and her material that is both physical and spatial. ${ }^{44}$ Once the Strung material entered my home it also entered my personal sphere, and with that came the first signs of recognition that the object had value, despite the fact that I was not yet sure of its function or even its aesthetic appeal. This came, too, with a sense of responsibility for engaging with the material and making something of it. As Ingold notes, it is through the act of making that the artisan couples her own life (spatially and bodily) with the active becoming of their materials. ${ }^{45}$ In the privacy of my living room, the Strung material was cut and knotted, taking on the new shape of ongoing and unexpected formations. 
It was here that I brought my movements into correspondence with those of the material, becoming mutually entangled in a web it created around me and my furniture (fig. 3).



Fig. 3. Material investigations for Strung. (Photo: T. Beer. Image courtesy of the author.) 


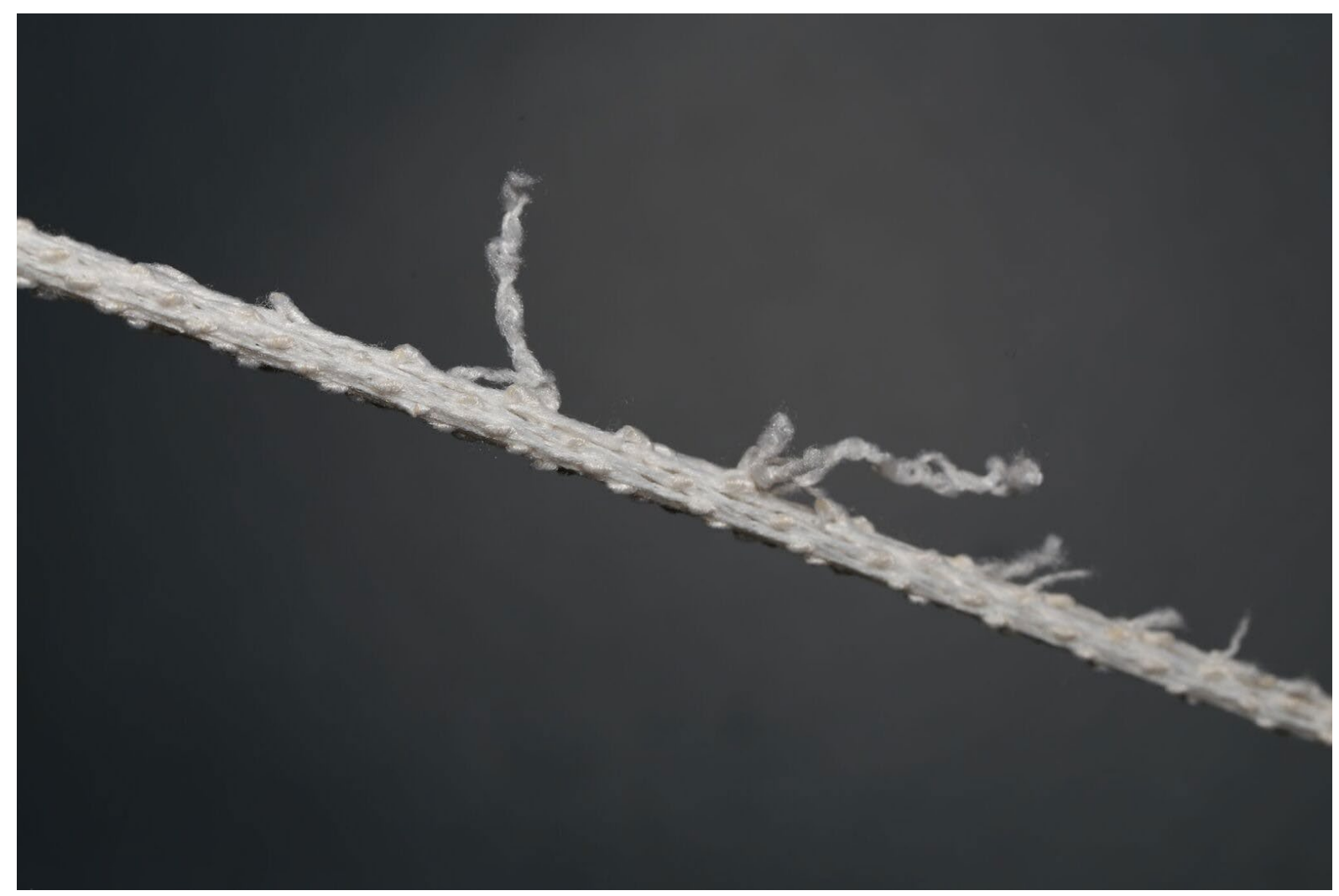

Fig. 4. Transforming the salami netting material. (Photo: T. Beer. Image courtesy of the author.)

During this act of transformation the first signs of the object's characteristics and potential began to reveal themselves (fig. 4). Ingold describes how "forms of things arise within fields of force and flows of material" 46 and it is through "joining with and following the forces and flows" that bring a work to fruition. ${ }^{47}$ However, in this act of following the "matter-flow" 48 of the salami netting, there was also an uncertainty, a concern that the overall function and aesthetic value of the material would not be pleasing, leaving me with a nervous anticipation of what might emerge. This feeling of uncertainty and "not-knowing" is also articulated by set designer Donyale Werle, who describes the turbulent process of working with salvaged materials in her interview in American Theater: "I work on the edge of disaster a lot," she explains, “and eventually it turns. It's nerve-wracking because you don't know when that'1l happen." ${ }^{49}$ Here, Werle reveals the tensions of working with the uncertain and serendipitous qualities of reclaimed materials. 
Creativity nonetheless arises from this often challenging region of flexibility, where the potential of an object or material only gradually becomes knowable. ${ }^{50}$ In the act of making, each gesture becomes a question "to which the material responds according to its bent," Ingold asserts. ${ }^{51}$ Here scenography might be likened to the work of an alchemist, a proto-science of working with and against established formulae that involves the "struggling with materials, and not quite understanding what is happening." 52 It was only after several hours of cutting and tying that the material for Strung began to unveil its hidden potential for the set design, taking on unexpected qualities of beauty and strength. From something that first appeared ugly and useless, the material had become exciting and valuable. It offered more scope than I had previously imagined. The material's elasticity demonstrated possibilities for stretching out lines through and across the performance space to build ephemeral networked structures that could also integrate the existing architectural features.

Werle explains that it is the materials that teach her, instead of the other way around. ${ }^{53}$ This suggests an act of "listening" to the material, or perhaps allowing it to "speak to you" as a way of accessing its potential. Werle notes, "I couldn't force a material to do what I wanted it to do." ${ }^{54}$ Hence working with found objects may be likened to both extracting and releasing the aesthetic potential of a material or artifact. For Ingold, the act of making is also a form of conversation whereby "things open up to the perceiver even as perceivers open up to them, becoming mutually entangled in that skein of movement and affect." 55 This concept of "making" thus encourages the scenographer to form a kind of dialogue or partnership with the materials.

\section{Strung (Cycles 1, 2, and 3): Displaying and Performing}

How a material or object is displayed or presented affects the way in which we value it; the distinction of worth is not intrinsic, but judged in relation to those around it. ${ }^{56}$ Strung 
was performed in three different environments, with each setting influencing the way the work was perceived.

Each performance began with the audience seated at the circumference of a circular edifice of white string attached to vertical pillars. At the center of the circle stood a performer dressed in a string costume made from six tubes of reclaimed cotton-elastic material. A small group of "active scenographers" entered the space and began connecting the performer to the suspended canopy, one piece of string at a time, thereby influencing the central performer's movements. Once each piece of string had been connected, the scenographers departed to the periphery of the space leaving the central performer to emerge out of the web, carefully freeing herself from the string, one costume piece at a time, resembling a butterfly emerging from a cocoon. As the performer departed the circle, her presence was left by the outline of the web, strikingly intact with elongated pieces of the costume debris left pendulous in the space. While Strung conjured up ideas of "interconnection," "entrapment," and "freedom," the work was essentially about responding to the material's attributes, rather than focusing on portraying a thematic idea. 


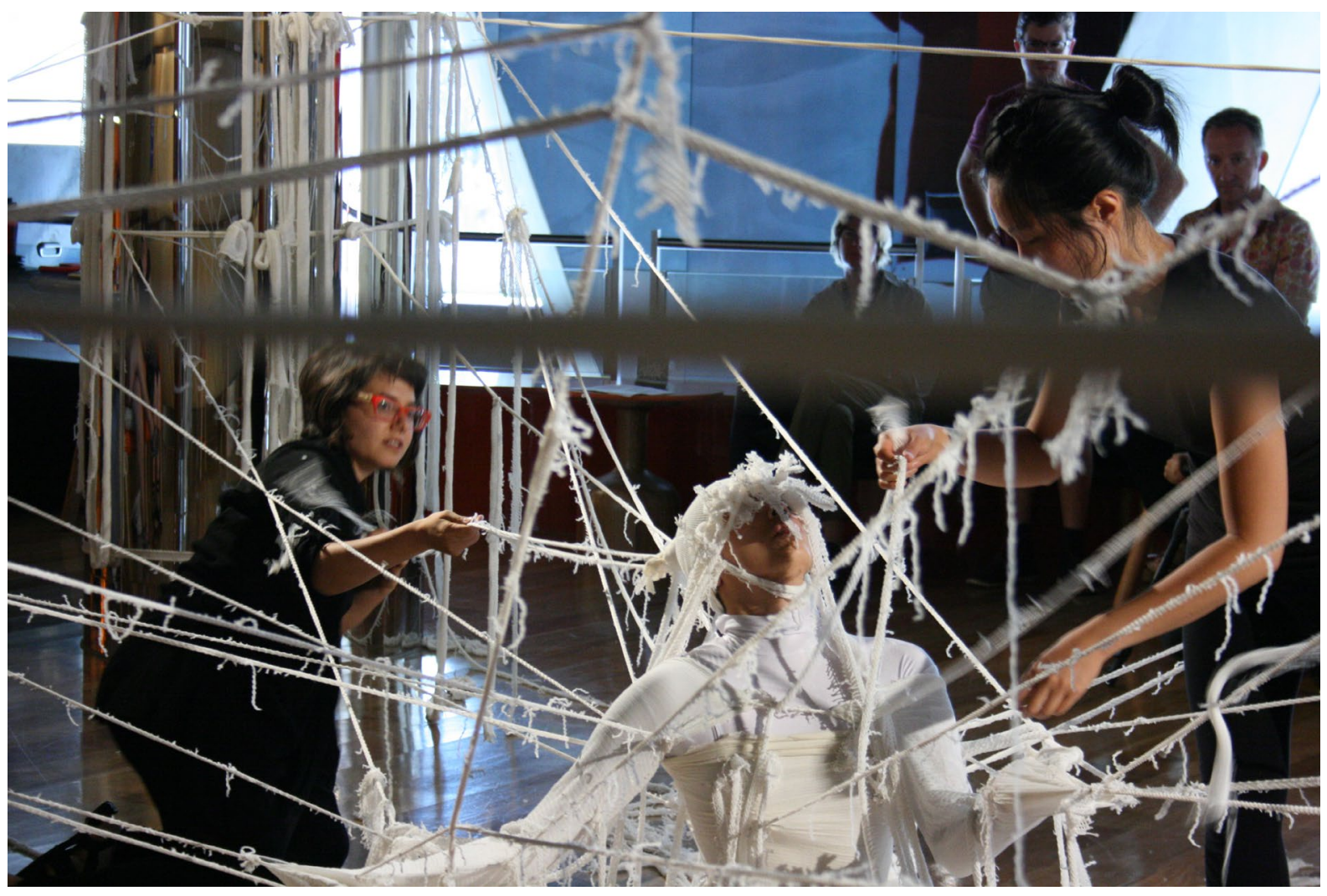

Fig. 5. Performing Strung (Cycle 1). (Photo: G.Beer. Image courtesy of the author.)

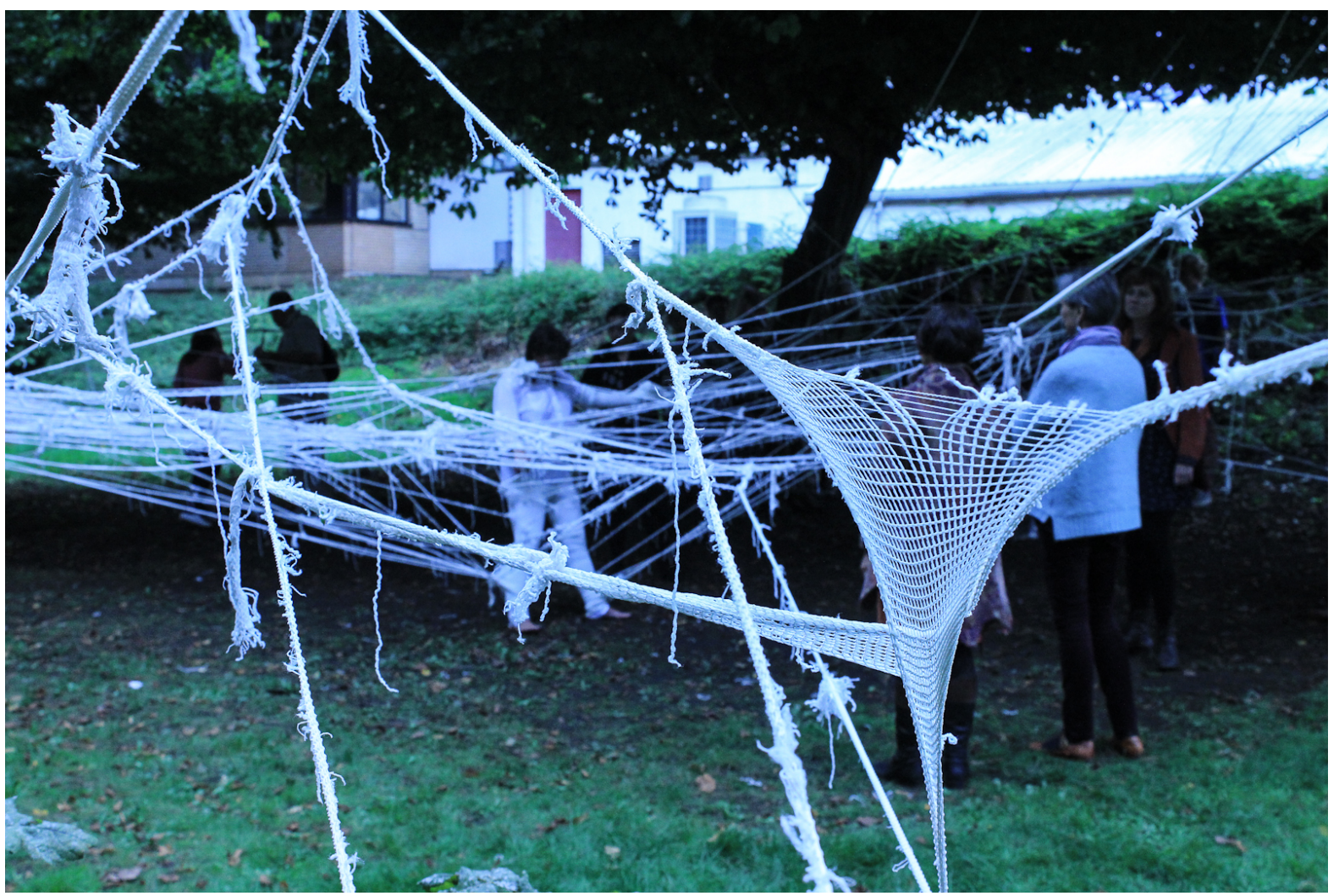

Fig. 6. Performing Strung (Cycle 1). (Photo: V. Pacchiani. Image courtesy of the author.) 
The first performance of Strung took place at the Hamer Hall (Cycle 1) —a high-art performing arts venue in Melbourne (fig. 5). In the context of this environment, it could be argued that the work was defined by the rich interior of the cultural precinct itself. Performing in a venue that was already seen as a "place of worth" elevated the material's perceived value. Set in the context of Hamer Hall, the salami netting became a means for connecting the performers and participants with the architectural elements of the space and for highlighting, in turn, the interconnectivity at work in both the materials and the performance itself.

The second performance (Cycle 2) took place in the exterior grounds of the Royal Welsh College in Cardiff as part of World Stage Design (fig. 6), which proved to be more challenging. The outdoor space lacked a definitive, appealing visual aesthetic or formality, which meant the work did not have the intrinsic focus, beauty, and intensity of its first performance. Strung demonstrated how the success of the work resulted from its situation in context. In this case, we lacked the addition of other scenographic elements (such as light and sound) to accentuate an inherently less accommodating space. As a result, the second iteration of the work became more of a workshop demonstration and an act of participatory engagement than a scenographic performance. Here, the audience participants were invited to enter the space and help construct the web.

The first two performance iterations of Strung developed and evolved in response to their individual environments and collaborators and the implications of each experience. Strung (Cycle 1) began by focusing explicitly on the act of choosing and engaging with the serendipitous possibilities of reclaimed materials, as well as testing the capacities for audience engagement. The successful audience participation in Melbourne prompted me to focus on this aspect of the work in Strung (Cycle 2) and benefited from engaging with the specialist knowledge of the World Stage Design (Cardiff) participants. As I mention above, 
however, in concentrating on participatory engagement, the project lost some of its visual aesthetic and performative potential. Thus there was a distinct choice to be made in staging the third iteration of Strung (Cycle 3), which involved returning to the performative side of the work: synthesizing the material and participatory elements to bring about a more cohesive presentation of the material's attributes.

The final performances of Strung (Cycle 3) took place in a black box studio space at the Royal Central School of Speech and Drama (Central) in London (fig. 7). New elements such as focused lighting, black curtains, and the addition of a live musician brought a higher degree of aesthetic focus to the work. An overhead rig permitted us to hang the material above the audience, thus allowing for a larger and more dynamic canopy to take shape rather than relying on existing vertical points based on existing architectural features of the performance space. Having multiple attachment points and possibilities available to us maximized the scope of the design to create a stunning material web. This version of Strung encouraged a more profound relationship with the string, highlighting the scenographers as active performers in the space and enhancing a stronger aesthetic engagement with the material. 


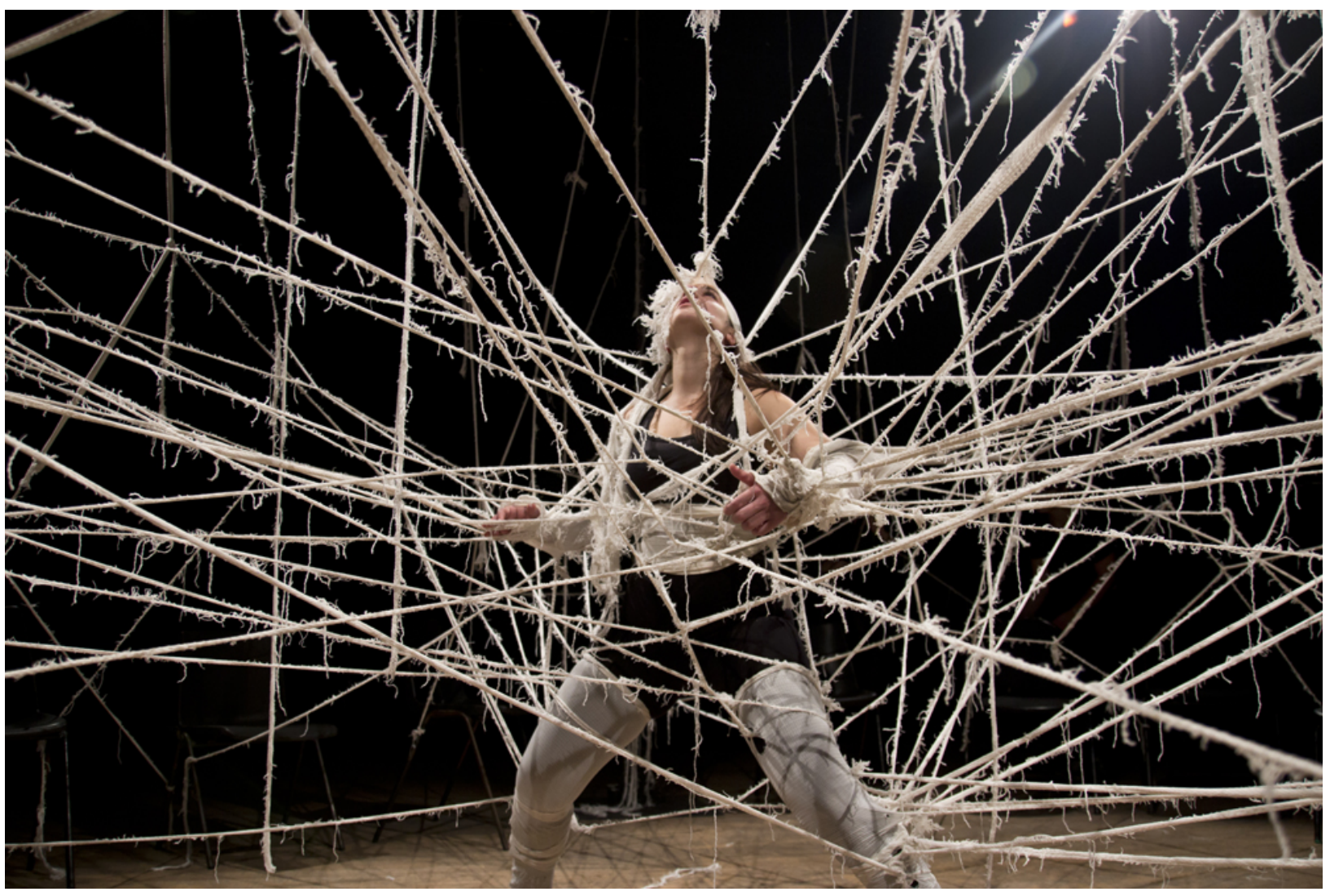

Fig. 7. Performing Strung (Cycle 3). (Photo: A. Murphy. Image courtesy of the author.)

All three cycles of Strung approached installation-making as a performance in order to demonstrate the potential of upcycling discarded material in the public realm. Each production redefined the traditional roles of designer and performer to integrate making and performing. The ensemble literally spun a web of material between them. For Ingold, making is already a "practice of weaving" in which practitioners create pathways or "lines of becoming" within the flow of the material. ${ }^{57}$ Throughout each cycle of Strung, this process became literal as well as metaphorical; we were following the string as "lines of flow" from one attachment point to another, allowing it to become "an active participant in the world's becoming." ${ }^{58}$ By engaging in this process, the ensemble played out ecological ideas of partnering and co-evolving with the more-than-human world. 


\section{Strung (Cycle 3): Transforming and Revealing}

In Melbourne, Cardiff, and London alike, the members of each Strung ensemble simultaneously became scenographers and performers, improvising their live actions among the assembled audience members, who eventually joined us in making the web. For Ingold, it is the dancer that "thinks from the body" while the artisan "thinks from materials," 59 but in the case of Strung, our process was spatial and haptic all at once. Incorporating an awareness of ecological complexity into the design process precipitated a more perceptive and fluid engagement with the materials, allowing a more conceptually reflexive relationship between material and human participants to occur.

The aim of the third iteration of Strung was to experience how a material might have agency, and how publically witnessing this potential vibrancy and complexity could allow for a renewed appreciation of the material — which now extended to the setting and the audience - far beyond its original purpose or destination. For performer Christina Kapadocha, Strung (Cycle 3) dramatized the experience of becoming a "vessel of unlimited experiential potentialities: of ideas, sensations, feelings, roles and performances" through one's participation in the event. ${ }^{60}$ Scenographer Jacquie Holland described Strung (Cycle 3) in more metaphysical terms as a "living, breathing, tangible creation that was sacred and fleeting," a statement that nonetheless testifies to the integrative and participatory workings of the performance. ${ }^{61}$ For me, it was about embracing the complexity of the material and physically surrendering to it, which meant moving my body according to the lines in space it created and following their lead. Such an act of following is, for Ingold, already the task of the performer: to be "alert to visual and other sensory cues in an ever-changing environment. ${ }^{92}$ For Kapadocha, Strung embodied precisely this alertness: the performance engaged in an "embodied dialogue with the 'otherness' of the material as 'second skin' in collaboration with the scenographers, music, audience and space." 63 


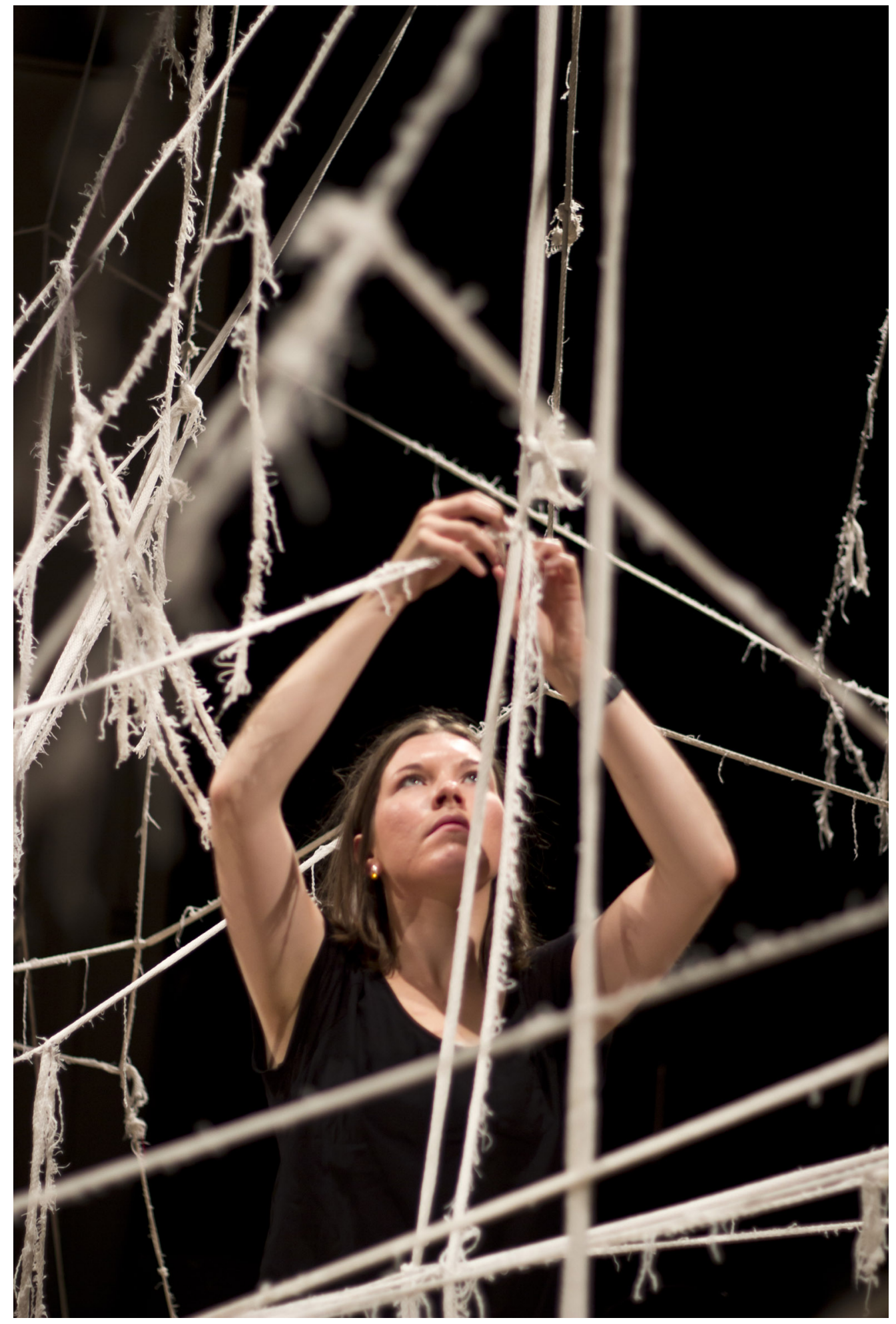

Fig. 8. Spinning a web of material (Strung, Cycle 3). (Photo: A. Murphy. Image courtesy of the author.) 




Fig. 9. Performing Strung (Cycle 3). (Photo: A. Murphy. Image courtesy of the author.)

Toward the end of the performance of Strung (Cycle 3), the audience was invited to enter the space and join us in the making of the web, allowing them to engage with the tactility of the material, creating shared memories and experiences. Each participant brought their own ideas and offered new statements on the visible sculpting of space in real time. We were improvising, simultaneously becoming scenographers and performers, knotting strings together and exploring the infinite possibilities of the growing web (figs. 8 and 9). As we worked, we allowed each string's individual length, thickness and elasticity to dictate how we moved and constructed the shape of the web.

\section{Strung (Cycle 3) and This Is Not Rubbish Craft Circle (Cycle 4): Transforming and}

\section{Reusing}

In the final performances of Strung (Cycle 3), the netting was beginning to be stretched beyond its capacity, often snapping when pulled too abruptly. The material was 
losing its beauty, too, along with its strength, becoming more dishevelled with each performance; it was signaling that it was time to move on and explore other potentialities. Engaging with the material after Strung required a willingness to accommodate its intraactive state of becoming and "to prioritize the processes of production over those of consumption." ${ }^{64}$ This meant considering anew the material's ecological aesthetic and imagining how the netting might be reinvented rather than discarded. The final iteration of the project, This Is Not Rubbish Craft Circle (Cycle 4), thus sought to transform the material used in all three performances into durable artifacts that could make a contribution to the broader community.

For Ingold, nothing is ever finished in a world of materials: "everything may be something, but being something is always on the way to becoming something else." 65 After the final showing of Strung (Cycle 3), we established a craft circle (Cycle 4) at the Central School of Speech and Drama (Central) in London to knit the material into wearable art and to auction off the items for charity. Through this act of "ongoing historicity" 66 we explored how ideas of upcycling might once again be incorporated into scenography as a way of recognizing the continuing value of material reuse and ecological potential beyond waste reduction and recycling.

This Is Not Rubbish craft circles attracted a small group of experienced and unexperienced knitters. We conceived of this process, too, as consistent with our ecological aesthetics. ${ }^{67}$ Handmade objects have stories embedded in their fabrication, the accumulated evidence of time and memory. ${ }^{68}$ Touched and molded by another body, handmade artifacts connect us to our living, ancestral, and cultural histories ${ }^{69}$ From the Strung material, the craft group worked together to knit a selection of accessories (scarves, shawls, hats) that would accrete monetary as well as merely sentimental value. A photo shoot yielded a fashion catalog featuring the objects, which were subsequently paired with costumes borrowed from 
Central's wardrobe department and modeled against a stylish set design during a display and auction for the Central School of Speech and Drama "Green Week" (fig. 10). The university held a silent auction that showcased the items as part of its sustainability event. A bidding sheet was circulated among the participants, asking them to place a monetary value on the artifacts. While the bids varied from item to item and from participant to participant, our highest bid of $£ 30$ (for hand knitted scarf) far exceeded the original price of the salami netting I originally purchased. The proceeds were donated to Dorney Residents Association to fund a community garden for a local hosting estate, thereby providing the possibility for a positive legacy to extend well beyond the project. 




Fig. 10. Photoshoot of wearable artefacts for This is Not Rubbish Craft Circle (Cycle 4). Photo: A.

Murphy. Image courtesy of the author.

This Is Not Rubbish Craft Circle (Cycle 4) sparked an additional project at the Central School of Speech and Drama. This project used discarded fabric offcuts from the costume department to create brightly colored brooches that could be sold during the School's Green Week. This project drew contributions from a number of the school's departments, with 
many of the staff and students wearing the brooches as a symbol of their commitment to environmental issues. From a $\$ 30$ AUD bag of salami netting and donated costume offcuts, we raised approximately $£ 340$ for the Dorney Residents Association, giving them a modest start to funding their project. 




11. Photoshoot of wearable artifacts for This is Not Rubbish Craft Circle (Cycle 4). (Photo: A. Murphy.

Image courtesy of the author.) 
Since the conclusion of This Is Not Rubbish in early 2014, the Dorney Residents Association moved ahead with its gardening plans. They received a grant from the UK Lottery Funds, and the local council donated water pipes. In addition, the Central School of Speech and Drama's sustainability officer continued to initiate creative projects that facilitate connections between students and local communities, bringing a new life into the university's existing sustainability model. By fostering an active engagement with the world beyond the theater, the project evolved and seeded the beginnings of other contributive practices.

\section{Ecoscenographic Outcomes of This Is Not Rubbish}

The ecoscenography of This Is Not Rubbish entailed taking a long view of aesthetics, materials, and ecological processes. As a result of my work on this project, I propose, first, that scenographers develop a more hands-on approach to seeking out the potentialities of their materials, an approach that dissolves the subject-object binary of scene design to engage in a "partnership" with matter. By asserting the lively intra-activity of things, the scenographer can begin to rethink her engagement with materials and gain a heightened awareness of the connections and unsustainable realities of the world.

My second proposal is that scenographers must realize that recycled materials and found objects comprise a valuable resource for pursuing high quality results without excess waste. This Is Not Rubbish demonstrates that there is much to be gained from rethinking, reconstructing, repersonalizing, and reimagining the value-material and conceptual as well as aesthetic and ethical — of discarded things. Place-based and serendipitous responses open up new avenues for scenographers to engage their audiences and communities in the making and sharing of ecological processes in and beyond an individual theatrical production. This Is 
Not Rubbish demonstrates the potential of upcycling refuse to influence our creative processes and yield new modes of practice.

The first step in integrating cyclical processes into scenographic practice involves grasping the fundamentals of ecological and intra-active systems. The question might now be posed, in turn, as to how this might be achieved in a theater industry so rooted in its mechanistic and linear framework. How can scenographers begin to shift toward a paradigm more conducive to the ecoscenographic model of cyclic engagement? And what are the ways in which projects like This Is Not Rubbish can be adapted toward more conventional performance considerations and practices?

Thinking beyond the ephemeral nature of opening night demonstrates a significant departure from the way in which scenographies are traditionally designed, constructed, and distributed. Scenographers are not usually contracted to consider post-production potential, of course, while the tight budgets, precarious funding availabilities, short production schedules, and rigid organizational structures of most theater companies allow few opportunities for experimentation or the engagement of communities in production processes. I contend, however, that there are ways for designers to consider a set material's eco-aesthetics and post-performance life, whether as a creative endeavor (as in This Is Not Rubbish) or more broadly as a charity donation beyond the theater. For example, opportunities exist for larger sets and materials to be donated to charity organizations for social initiatives (such as community gardens, schools, Men's Sheds, and childcare centers). A theater company could also use its education or outreach programs to partner with designers to conduct workshops that included the repurposing of set materials for specific community events.

While embracing ecoscenography in the temporary landscape of theater remains "sacred and fleeting," to cite Jacquie Holland, I posit that theater can no longer defend practices that disregard the fragility of our environment in favor of momentary spectacle and 
monetary sustainability alone. As we move toward an increasingly uncertain future, scenographers must ultimately learn not only to reimagine scenography's ruins, but also to phase out the idea of waste altogether. We then will begin to witness the creative potential of designing in tune with material, cultural, social, and ecological systems that extend far beyond the measures of eco-efficiency alone.

\section{Bio:}

Tanja Beer is a scenographer and Research Fellow investigating ecological design for performance at the University of Melbourne, Australia. Tanja has exhibited designs in London, Cardiff, Glasgow, Melbourne, Sydney, Brisbane, Vienna, and Tokyo. She has a Masters in Stage Design (Universität für Musik und Darstellende Kunst Graz, Austria), a Graduate Diploma in Performance Making (Victorian College of the Arts, Australia), and has had ecoscenography work selected for the Make/Believe British exhibit at the 2015 Prague Quadrennial and V\&A Museum (London).

\section{Notes}

${ }^{1}$ See, for example, Damond Morris, Towards a Recycled Theatre: Industrial Ecology Theatrical Applications for the Next Industrial Revolution (Bellingham, WA: Western Washington University, 2007).

${ }^{2}$ See Tanja Beer, “The Living Stage: A Case Study in Ecoscenography," Etudes 1, no. 1 (2015), http://www.etudesonline.com/uploads/2/9/7/7/29773929/etudesfeb2015beer.pdf. 
${ }^{3}$ Images and film recordings of This is Not Rubbish can be accessed online via http://www.tanjabeer.com/strung-this-is-not-rubbish.

${ }^{4}$ For an example of research in this field, see Dorita Hannah and Olav Harsløf, Performance Design (Copenhagen: Museum Tusculanum Press, University of Copenhagen, 2008).

${ }^{5}$ Dorita Hannah, "Constructing Barricades and Creating Borderline Events," Theatre and Performance Design 1-2, no. 1 (2015): 128.

${ }^{6}$ See: Tanja Beer, “Ecoscenography,” 2014, www.ecoscenography.com.

${ }^{7}$ By "aesthetic experience," I refer to the bodily encounter (e.g., visual, audible, kinaesthetic, tactile, olfactory, somatic, gustatory, spatial, and durational) of perception, a concept informed the philosophical discourse of Maurice Merleau-Ponty and concerned with the reciprocal connection of perceiver and object.

${ }^{8}$ Paul H. Gobster, “An Ecological Aesthetic for Forest Landscape Management," Landscape Journal 18, no. 1 (1999), 61.

${ }^{9}$ Tanja Beer, "Ecomaterialism in Scenography," Theatre and Performance Design (Forthcoming).

${ }^{10}$ Igor Kopytoff, "The Cultural Biography of Things: Commoditization as Process," in The Social Life of Things: Commodities in Cultural Perspective, ed. Arjun Appadurai (New York: Cambridge University Press, 1988), 64-91.

${ }^{11}$ Tim Dant, Material Culture in the Social World: Values, Activities, Lifestyles (Buckingham: Open University Press, 1999).

${ }^{12}$ Liz Parsons, “Thompsons' Rubbish Theory: Exploring the Practices of Value Creation," Advances In Consumer Research - European Conference Proceedings 8 (2008), 392.

${ }^{13}$ Ibid. 
${ }^{14}$ See Michael Thompson, Rubbish Theory: The Creation and Destruction of Value (Oxford: Oxford University Press, 1979).

${ }^{15}$ For example, see the work of designers Donyale Werle (U.S.), Soutra Gilmour (UK) and Anna Tregloan (Australia).

${ }^{16}$ Kay Thornton, “Salvo in Germany: Reiner Pilz,” Salvo News 99 (1994), 11-14.

${ }^{17}$ William McDonough and Michael Braungart, The Upcycle (New York: North Point Press, 2013).

${ }^{18}$ Rebecca Earley, Worn Again: Rethinking Recycled Textiles 2005-2009 (London: Arts and Humanities Research Council, 2011, 3.

${ }^{19}$ Ibid.

${ }^{20}$ Parsons, “Thompsons' Rubbish Theory,” 392.

${ }^{21}$ Donyale Werle is quoted in Christopher Kompanek, "For Donyale Werle It's Easy Being Green," American Theatre (2012), 31.

${ }^{22}$ Martina Margetts, “Action Not Words," in Power of Making, ed. Daniel Charny (London: V\&A Publishing, 2011), 39.

${ }^{23}$ Tim Ingold, “The Textility of Making," Cambridge Journal of Economics 34, no. 1 (2010), 91-102.

${ }^{24}$ Gilles Deleuze and Félix Guattari, A Thousand Plateaus: Capitalism and Schizophrenia, trans. Brian Massumi (London: Continuum, 2004), 454 and 451.

25 Tim Ingold, “Toward an Ecology of Materials," Annual Review of Anthropology 41, no. 1 (2012): 431.

${ }^{26}$ Ingold, "The Textility of Making," 96.

${ }^{27}$ Karen Barad, Meeting the Universe Halfway: Quantum Physics and the Entanglement of Matter and Meaning (Durham: Duke University Press, 2007), 128. 
${ }^{28}$ Karen Barad, "Posthumanist Performativity: Toward an Understanding of How Matter Comes to Matter," Signs: Journal of Women in Culture and Society 28, no. 3 (2003), $801-831 ; 821$.

${ }^{29}$ Ibid., 822.

${ }^{30}$ Ibid., 803.

${ }^{31}$ The project used action research as a key approach to the practice-led investigation, which followed an iterative spiral of "plan, act, observe and reflect" as discussed by Ortrun Zuber-Skerritt, Action Research in Higher Education: Examples and Reflections (London: Kogan Page, 1992).

${ }^{32}$ This Is Not Rubbish was completed as part of a residency exchange with the Central School of Speech and Drama, London, UK (September 2013-February 2014).

${ }^{33}$ I use the term "co-extensive potential" to describe the idea of being concerned with the possible "unseen" ecological effects of scenography: that which may not be immediately evident in the making of the work (unrecyclable set elements, toxic enamel spray paints, and \$2 shop props) but we acknowledge has causational potential to form a negative by-product of the "visible" and "experienced" (adding to landfill waste, air pollution, and the production of child labor).

${ }^{34}$ Parsons, “Thompsons' Rubbish Theory,” 392.

${ }^{35}$ Ibid.

${ }^{36}$ Ingold argues that "anything we come across could, in principle, be regarded as either an object or a sample of material." See Ingold, “Toward an Ecology of Materials,” 435.

${ }^{37}$ Ibid., 435.

${ }^{38}$ Ibid., 433.

${ }^{39}$ Pamela Howard, What Is Scenography? 2nd ed. (New York: Routledge 2009): 135. 
${ }^{40}$ Dant, Material Culture, 128.

${ }^{41}$ Ibid., 154.

${ }^{42}$ Ingold, "Toward an Ecology of Materials," 437.

${ }^{43}$ Parsons, “Thompsons' Rubbish Theory,” 392.

${ }^{44}$ Dant, Material Culture, 144.

${ }^{45}$ Ingold, "Toward an Ecology of Materials," 435.

${ }^{46}$ Ingold, "The Textility of Making," 91.

${ }^{47}$ Ingold, "Toward an Ecology of Materials," 435.

${ }^{48}$ Deleuze and Guattari, A Thousand Plateaus, 454.

${ }^{49}$ Werle in Kompanek, "For Donyale Werle It's Easy," 30.

${ }^{50}$ Thompson, Rubbish Theory, 8.

${ }^{51}$ Ingold, "Toward an Ecology of Materials," 435.

52 James Elkins. What Painting Is: How to Think about Oil Painting, Using the Language of Alchemy (New York: Routledge, 1999), 17.

${ }^{53}$ Werle, in Kompanek, "For Donyale Werle It's Easy," 31.

${ }^{54}$ Ibid.

${ }^{55}$ Ingold, "Toward an Ecology of Materials," 435.

${ }^{56}$ Parsons, “Thompsons’ Rubbish Theory,” 392.

${ }^{57}$ Ingold, “The Textility of Making," 91.

${ }^{58}$ Barad, "Posthumanist Performativity," 803.

${ }^{59}$ Ingold, "Toward an Ecology of Materials," 437.

${ }^{60}$ Tanja Beer, Christina Kapadocha, and Jacquie Holland, "Strung: The Story Behind the Postcard," Blue Pages: Journal for the Society of British Theatre Designers 3 (2014): 26. ${ }^{61}$ Ibid. 
${ }^{62}$ Ingold describes practitioners or makers as "wanderers, wayfarers, whose skill lies in their ability to find the grain of the world's becoming and to follow its course while bending it to their evolving purpose" (“The Textility of Making," 91).

${ }^{63}$ Beer et al., "Strung," 26.

64 Jane Bennett. Vibrant Matter: A political Ecology of Things (Durham: Duke University Press, 2010), ix.

${ }^{65}$ Ingold, "Toward an Ecology of Materials," 435; Tim Ingold, "Introduction," in Redrawing Anthropology: Materials, Movements, Lines, ed. Tim Ingold (Farnham: Ashgate Publishing Ltd, 2013): 3.

${ }^{66}$ Barad, "Posthumanist Performativity," 821.

${ }^{67}$ According to Margetts in "Action Not Words," making can be described as an act of producing happiness, flow and pleasure that is "experienced by the maker and transmitted through the work to the viewer" (40).

${ }^{68}$ Ibid.

${ }^{69}$ Rosie Greenlees and Mark Jones, "Foreword," in Power of Making, ed. Daniel Charny (London: V\&A Publishing, 2011): 5. 